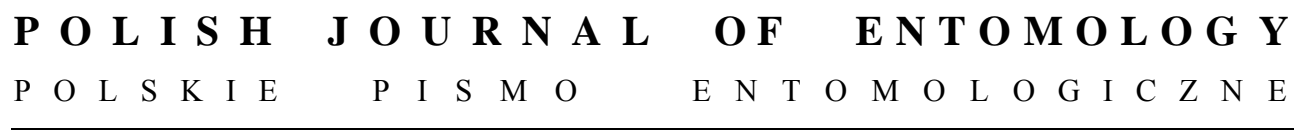

VOL. 81: $165-183$

Gdańsk

30 June 2012

DOI: $10.2478 / \mathrm{v} 10200-012-0005-\mathrm{z}$

\title{
On Baltic amber inclusions treated in an autoclave
}

\author{
CHRISTEL HOFFEINS
}

\author{
Liseistieg 10, D-22149 Hamburg, Germany \\ chw.hoffeins@googlemail.com
}

\begin{abstract}
Inclusions from Baltic amber processed in an autoclave are described, illustrated, and the various degrees of artificial modifications are commented upon. To inform entomologists and palaeontologists with less experience in amber and inclusions, general information on improved inclusions is given.
\end{abstract}

KEY WORDS: Baltic amber, improved amber, autoclave, inclusions, artificial modification.

\section{INTRODUCTION}

Inclusions in Baltic amber open a fascinating window into the past of a vanished world. Many people are attracted to the beautiful organisms entombed in a golden coffin. The external characters of inclusions can be studied thanks to their preservation, which is almost as good as examining living arthropods. This is why amber is so famous and treasured by the public as well as by the scientific community.

In the last decade there have been increasing numbers of inclusions selected from autoclave-treated amber. Autoclave processing, also referred to as "ennoblement" in the sense of 'upgrading' the beauty and natural preservation of inclusions, is often a change in the sense of "degradation". Amber treated and clarified in autoclaves is marketed as "improved" amber.

Why is an autoclave used for amber?

Amber companies use autoclaves to clarify opaque amber and to obtain a cognac-like colour. Autoclaving works with pressures of 90-150BAR, the addition of nitrogen or argon 
gas and temperatures up to $200^{\circ} \mathrm{C}$. Persons employed in this procedure need a high level of experience if the desired result is to be obtained. Amber clarification also has a long historical tradition: the Romans and medieval craftsmen used boiling oil or slowly heated it in sand and salt beds.

Nowadays, a clear cognac- or honey-coloured amber is considered to be "typical" amber and more precious, generally because most people are not familiar with the rich variety of natural amber colours. On completion of the autoclave processing, clarified amber inclusions, previously concealed in the opaque amber, become visible.

The prices for trade quantities of amber have increased year by year, so many companies have started to treat large quantities of the so-called "Schlauben" or "sklejka", a cheaper quality of raw layered amber.

Layered amber was formed by successive resin flows outside the bark of the amber tree, sometimes up to 100 in large samples, and the surface of each layer was as sticky as flypaper. The percentage of inclusions is higher than normally found in unlayered amber pieces. Schlauben are very brittle and cannot be cut for beads or other products. But after treatment in an autoclave the layers are permanently bound, and can then be cut and trimmed without difficulty or loss of prized material.

A side-effect of clarifying and Schlauben processing is the large amount of autoclaved inclusion material available on the market.

Ordinary people buying amber products cannot usually see any differences between natural and autoclaved amber, or between inclusions in their natural condition and those treated in an autoclave.

But a scientist studying the fauna and flora embedded in Baltic amber may encounter a problem, especially if he/she is inexperienced and studying inclusions for the first time. The following considerations are general information about the changes taking place in inclusions after improvement in autoclaves.

\section{Artificial changes in amber after autoclave processing}

During autoclave processing the amber is subjected to high pressure and high temperature. What happens to the amber matrix itself inside such a furnace?

We cannot open the autoclave and check the microscopic details within an amber sample while this treatment is going on. But we can document the results and interpret the changes in the amber matrix, and test physical and chemical characteristics such as hardness or amber acid content.

The main changes taking place in the amber matrix during autoclave processing are:

- clarification by the diffusion of micro-bubbles;

- the absence of amber acid, a typical component of Baltic amber;

- the absence of the typical pine-resin smell; 
- the intensification of pale colour of the resin flow layers to a brownish-orange hue, while the main amber matrix remains watery and clear;

- the occasional presence of bluish to greenish veils along the margins of resin flows within layered amber.

\section{Acknowledgements}

My sincere thanks go to Prof. Ryszard Szadziewski for encouraging me to deal with autoclaved inclusions and for his critical comments. My husband Hans Werner Hoffeins is thanked for preparing some photographs and an anonymous reviewer for improving the English draft.

\section{MATERIAL AND METHODS}

Christel \& Hans Werner Hoffeins Collection, Hamburg, Germany (CCHH), to be deposited at the Senckenberg Deutsches Entomologisches Institut, Müncheberg (SDEI). The photographs were taken with a Nikon Coolpix 4500 attached to a Wild M3Z stereomicroscope and edited with IrfanView.

\section{RESULTS AND DISCUSSION}

\section{General remarks}

A "natural" inclusion is defined by the nearly exact original form of its outer shape (Fig. 1). We can find all degrees of preservation, ranging from the beautiful and perfect to the scarcely identifiable. It depends upon the condition at the very moment when the organism was entrapped by the flowing resin: alive and complete, dead, or already somewhat decayed.

In contrast to compression fossils, inclusions in amber are fossilized in three dimensions. The body lumen can be completely filled with resin or empty, the inner organs decayed or partly mummified. In normal cases we find just the outer shape of arthropods, like insects and spiders, including the cuticle with hairs, bristles and scales present in the original position. Body and wings are discoloured except for the metallic colours in some Coleoptera, the dipteran family Dolichopodidae and in the hymenopteran family Torymidae (pers. observation). Rarely, wing markings are present as well, mostly in Cicadina, Trichoptera, Mecoptera, Neuroptera, Blattodea, Embioptera and some Coleoptera (WEITSCHAT \& WICHARD 1998).

A phenomenon typical of Baltic amber inclusions is a milky coating or emulsion (German term: "Verlumung") obscuring the morphological details of the embedded organisms. The cloudy coating occurs in all degrees of intensity, but often it just covers 
inclusions on one side, or more or less totally and around body openings such as spiracles, terminalia and mouthparts. It is assumed that the milky emulsion is caused by the decomposition of gases or general moisture surrounding the embedded organisms, not exclusively found in insects and other arthropods but also in plants and plant debris. The phenomenon was discussed in detail by SCHLÜTER \& KÜHNE (1975) and MIERZEJEWSKI (1978).

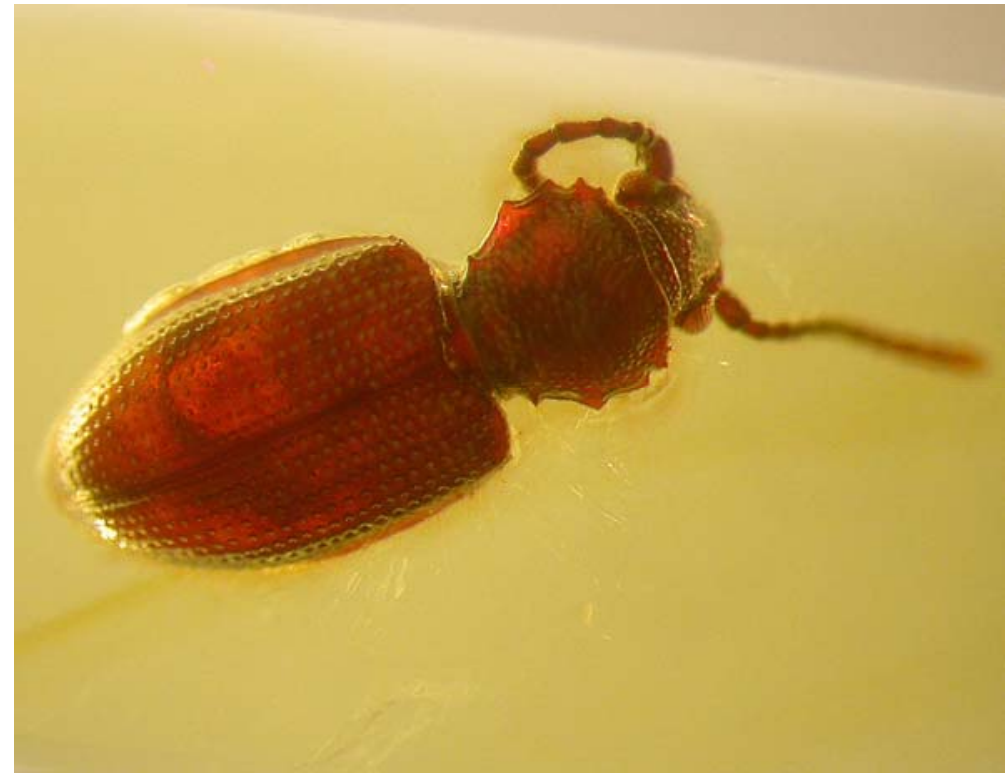

Fig. 1. Silvanidae (Coleoptera), undescribed sp., dorsal habitus, showing a vivid preservation in natural amber, coll. 1698-4.

When amber is clarified in autoclaves, the embedded organic inclusions undergo an artificial change.

As in a furnace, the high temperature can produce more or less severe deformations of the embedded objects. The organisms are heated, dry out and finally roasted to be as burnt as a broiled chicken. The surface of the inclusion turns dark brown and black; body and legs are deformed, shrunk or compressed; bristles and hairs may have lost their original point of insertion; the veins on the wings may be cracked and the delicate wing membrane destroyed. Often the body and especially the wings are surrounded by an orange-brownish aureole-like veil (Fig. 2). Inside the aureole there may be dark micro-fissures or microcracks resembling tiny setulae.

Even if a fly's corpse and legs are shrunk, collapsed or deformed, the bristles on the body remain their normal length, so the original ratio of measurements may change. This 
has to be taken into account, especially when identifying Diptera placed in the section Acalyptratae (VON TSCHIRNHAUS \& HofFEINS 2009). The integument of the legs becomes transparent so that mummified fragments are visible as thin black strings.

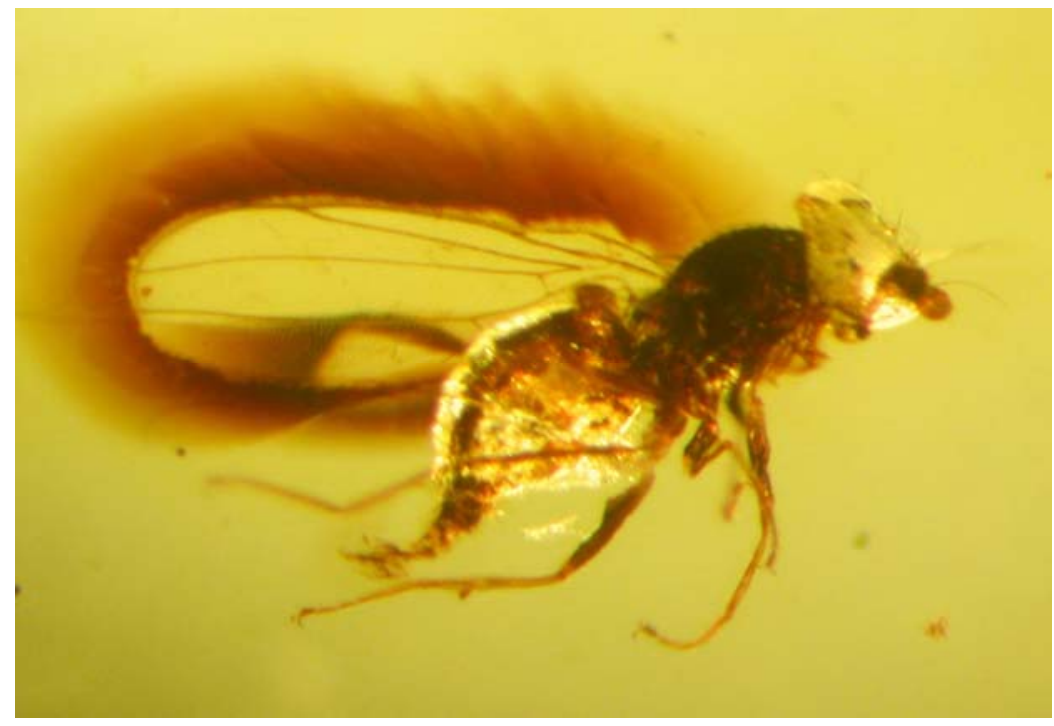

Fig. 2. cf. Asteiidae (Diptera: Acalyptratae), female, treated in an autoclave, coll. 668-4.

In the worst case, the inclusion may be totally deformed, blasted by heating into small particles so that only the previous shape of the organism is present.

But we often find improved amber with inclusions that look almost like natural inclusions, although it is quite obvious that the amber has been subjected to thermal treatment. These organisms show just a low degree of alteration, if any at all. A possible reason for this is the presence of a milky emulsion covering the inclusions. Consisting of microbubbles and resin, the coating seems to act as a protective shell against strong heating. After autoclave processing the microbubbles have disappeared by diffusion, have combined to form larger ones or are filled with resin, so that the once-obscured organisms can now be studied in detail. This physical alteration may explain the presence of irregularly shaped, resin-filled and shiny bubbles adhering or close to autoclaved inclusions (Figs 5, 14). These flat bubbles are quite different from those found in natural amber.

Also, it appears that Acari or Coleoptera and Blattodea are often protected against high temperature and atmospheric pressure by their strong, sclerotized elytra, in contrast to more delicate insects like Diptera, Aphidina and Thysanoptera.

Some observations have been made concerning the position of inclusions in relation to the size of amber samples. An organism embedded closer to the surface of an amber piece 
shows a higher degree of roasting compared to inclusions positioned near the centre. Organisms embedded in large amber samples some centimetres in size are often roasted to a lesser degree than those in small cabochons of about 5-10 mm.

In general, autoclaved inclusions covered with or without a milky emulsion reveal a broad range of gradual deformation, roasting and external damage.

In the following, some selected specimens, mainly dipteran inclusions, showing the gradual alterations caused by autoclave processing are described, illustrated and commented upon.

\section{Case studies}

Ceratopogonidae (Diptera), male, Forcipomyia sp., $1.8 \mathrm{~mm}$

(Fig. 3)

The midge inclusion is embedded in a watery, clear amber; head, thorax and abdomen with genitalia black and roasted; antenna, palpi and wing venation in good condition; legs and basal abdominal segments transparent with internal black fragments; genital complex discernible except for minute appendages inside the clasper.

Main diagnostic features present and identification to genus level possible.

Autoclave processing did not cause serious alterations.

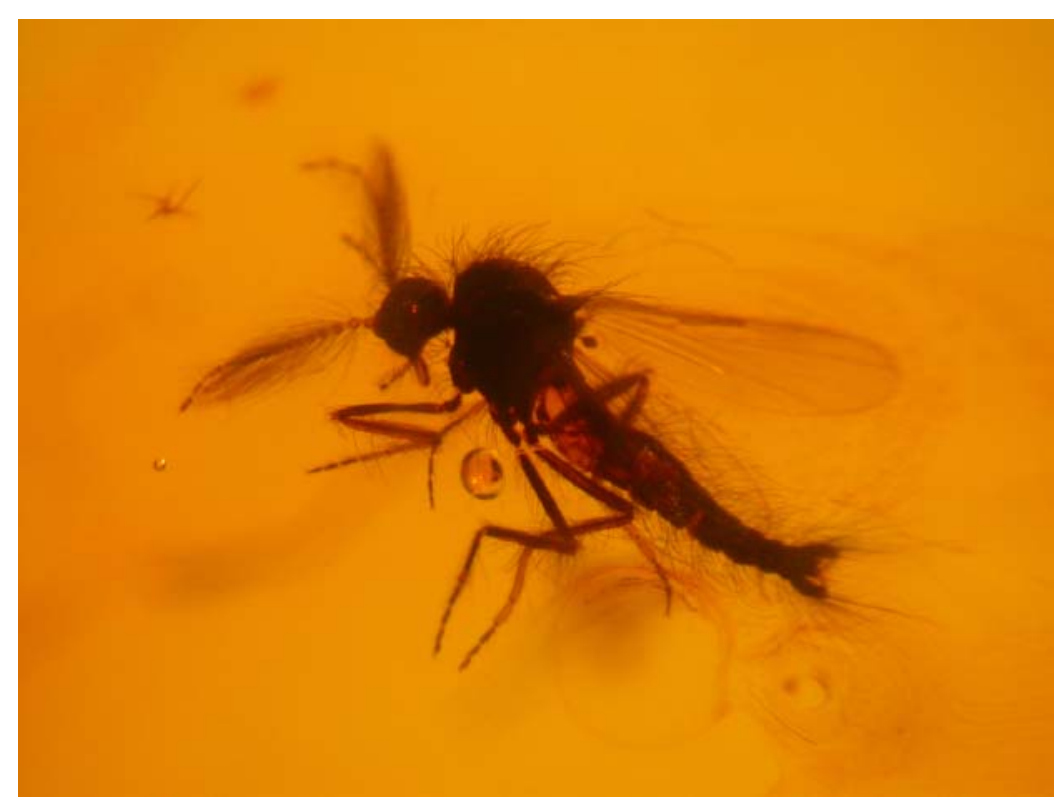

Fig. 3. Ceratopogonidae (Diptera: Nematocera), Forcipomyia sp., male, coll. 179-2. 


\section{Mycetophilidae (Diptera), Mycomyia sp., male, $5.3 \mathrm{~mm}$}

(Fig. 4)

The gnat inclusion is embedded in a multi-layered amber piece is in a somewhat decayed condition, left eye with irregular rounded hole, a damage often seen in eroded inclusions which were not covered totally by resin flow, tarsi and flagellomeres of antenna partly disconnected. Thorax and coxae roasted and amorphous, without any morphological details; palps, haltere and fore femur transparent, thorax, femora and tibia laterally compressed; wings basally disarticulated, costa and radial veins partly cracked, wing membrane partly lacerated; shape of sclerotized genitalia including all appendages intact, some inner soft appendages transparent. Although the thorax is roasted and amorphous, the right eye with ommatidia is complete and in a well preserved condition.

Autoclave processing did not cause serious alterations, identification to genus and even species level possible due to the discernible genitalia complex.

The cracks and breakages in the wing membranes and the antenna do not appear natural and most probably result from the autoclave process as wings of a recently trapped insect would still be flexible in soft resin.

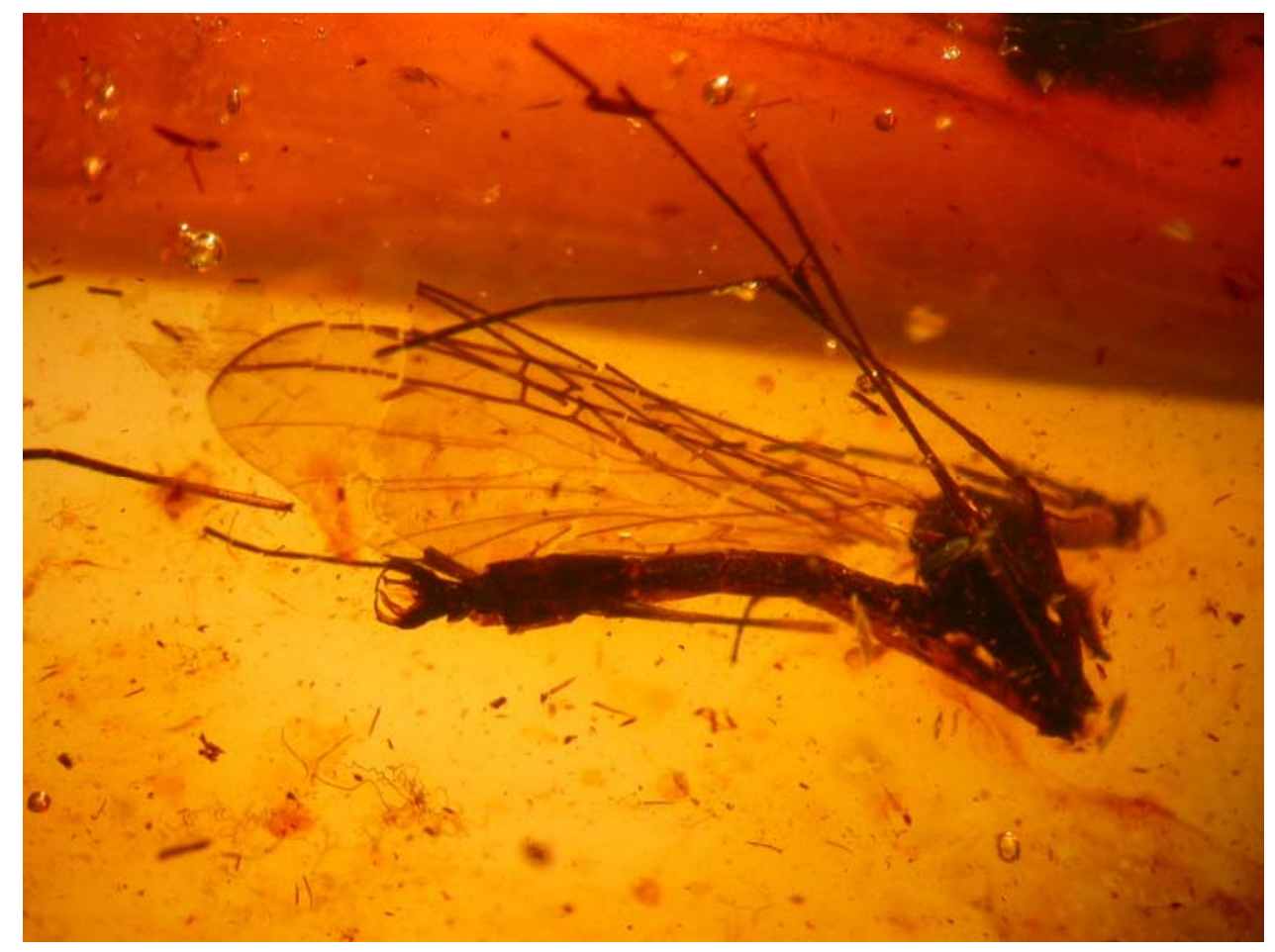

Fig. 4. Mycetophilidae (Diptera: Nematocera), Mycomyia sp., male, coll. 1735-4. 


\section{Sciomyzidae (Diptera: Acalyptratae), cf. Phaeomyiinae, female, $4.4 \mathrm{~mm}$ Syninclusion cf. Sminthuridae (Collembola), $0.7 \mathrm{~mm}$}

(Figs 5, 6)

The dipteran inclusion is complete with the right side of the thorax, head and all legs in good condition, left side of body with eye, postcranium, proboscis, thorax and coxae collapsed, no morphological details visible; antenna roasted, frons with frontal setae obscured by a resin-filled transparent bubble; thorax slightly compressed laterally as seen in the dorsal view, mesonotal proportions lengthened, transverse suture destroyed, surface of mesonotum somewhat amorphous; thorax with humeral and presutural macrochaeta disconnected, structure of left outer vertical and postalar bristles cracked; wings with radial veins cracked, wing membrane broken up into several parts; abdomen with female cerci well preserved.

Autoclave processing produced some artificial changes but identification to family and subfamily level is possible due to the presence of the median anterior bristle on the mid femur and short posterior setae on the hind tibia.

Next to the dipteran inclusion a minute collembola is embedded. The springtail inclusion is totally destroyed; head with eyes and abdomen disconnected from the thorax, eyes with body transparent, furca and antenna faint, diagnostic details not discernible.

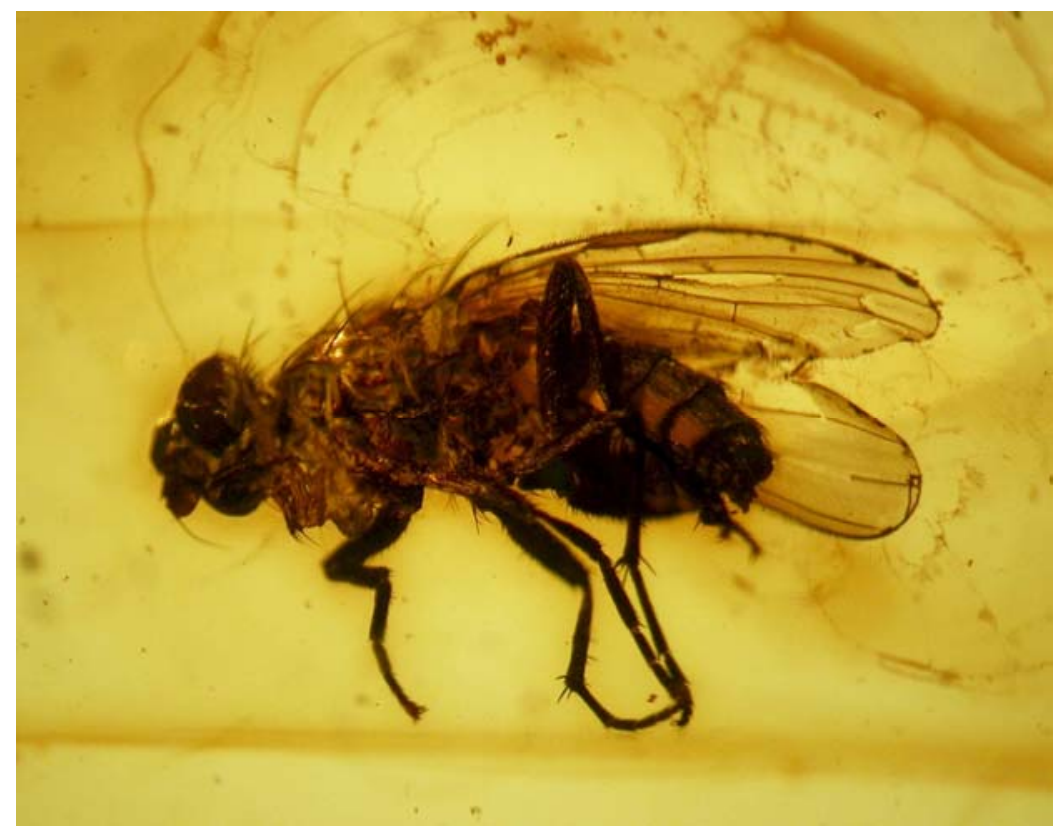

Fig. 5. Sciomyzidae (Diptera: Acalyptratae), cf. Phaeomyiinae, female, coll. 1104-4. 


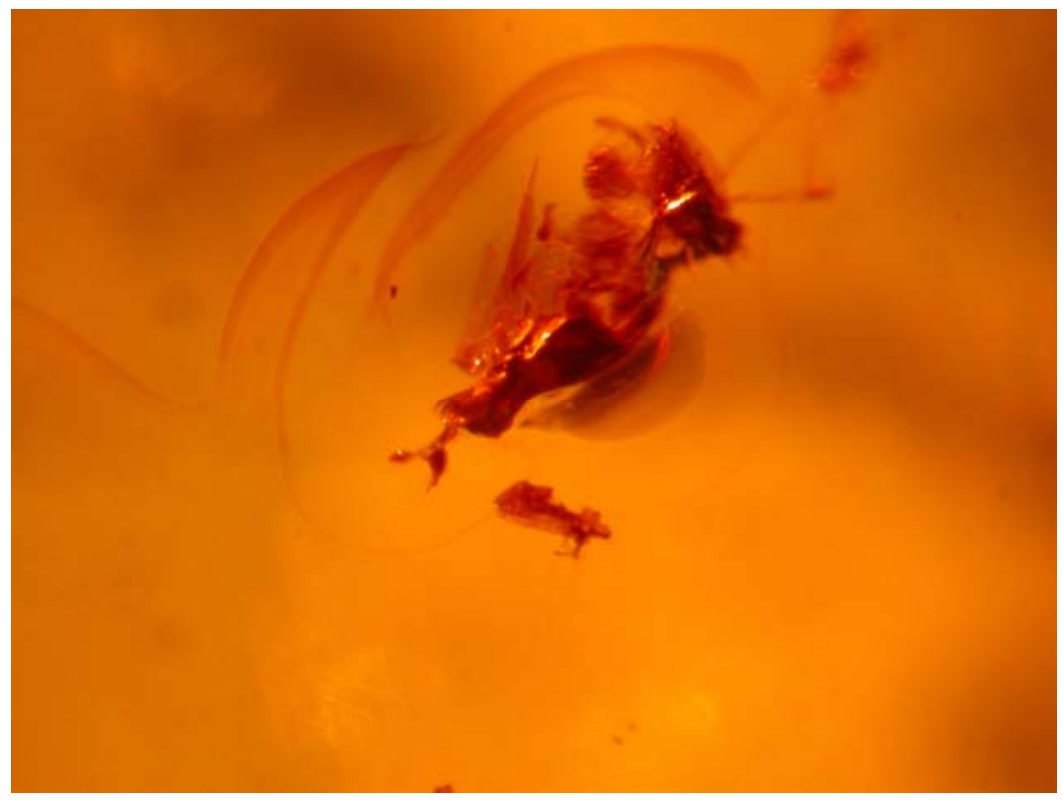

Fig. 6. cf. Sminthuridae (Collembola), syninclusion, coll. 1104-4.

Autoclave processing caused serious modifications; identification to family level depends on the general habitus of the collembolan fragments.

In the amber piece with Diptera and Collembola inclusions we find two different degrees of deformation. The large inclusion is more or less intact and shows just a low level of deformation whereas the minute one is totally destroyed. We can assume that the degree of artificial modification must be considered in relation to the size of an organism. Note: the layered amber shows a highly intense orange-brown colouration along the margins of the resin flows.

\section{Stratiomyiidae (Diptera), Pachygastrinae, female, $2.5 \mathrm{~mm}$}

(Figs 7, 8)

A soldier fly inclusion embedded in a watery, clear amber, surrounded by a fine aureole; head brownish to black and roasted, eyes not collapsed, antenna roasted, segmentation not discernible but arista transparent and micro-morphological details present including apical seta on tip; cervix somewhat elongated artificially; thorax black, roasted and laterally compressed, without any morphological details, setosity of mesonotum distinct, legs transparent with internal black fragments, wings in good condition with venation complete, membrane dark orange-coloured; abdomen black and roasted, female terminalia indistinct without any external details. 


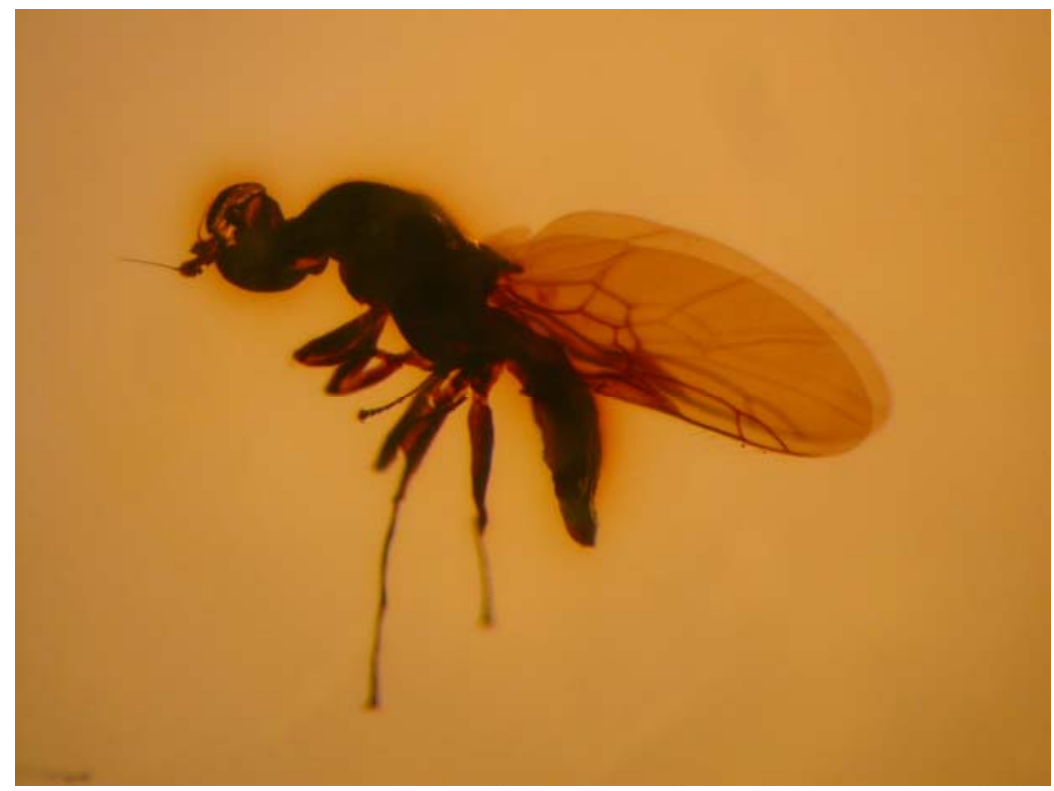

Fig. 7. Stratiomyiidae (Diptera), Pachygastrinae, autoclaved female, lateral habitus, coll. 1350-2.

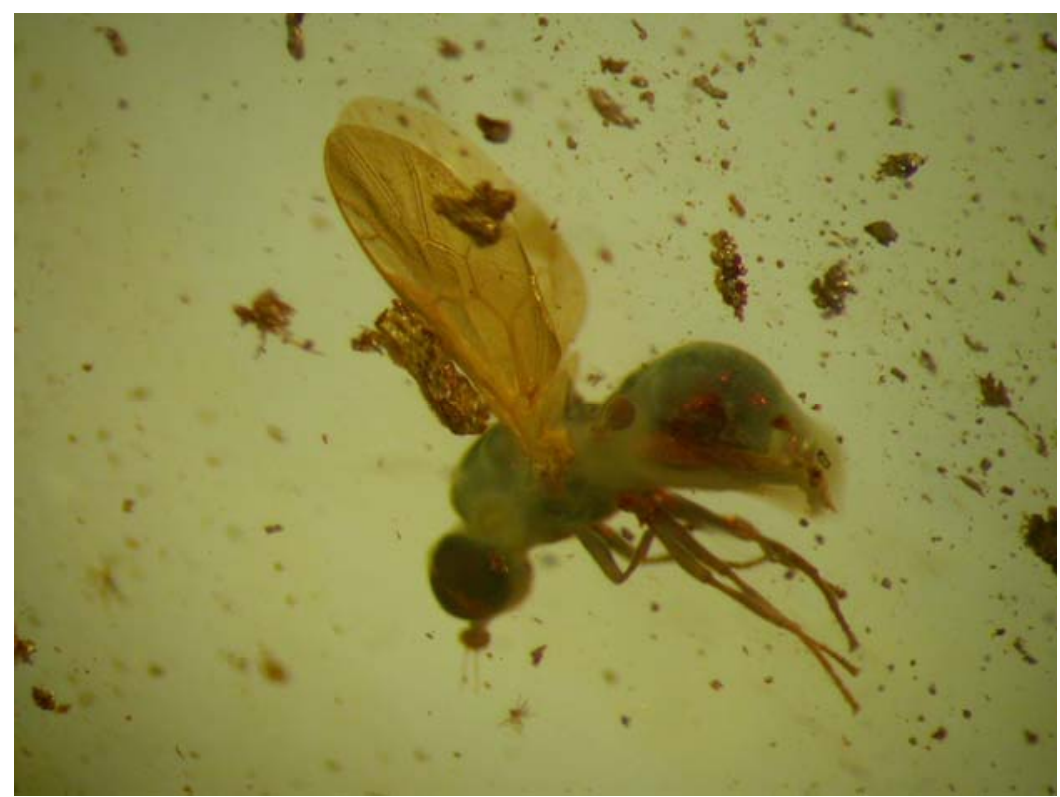

Fig. 8. Stratiomyiidae (Diptera), Pachygastrinae, female, lateral habitus, natural amber, body obscured by milky coating, coll. 1350-1. 
Autoclave processing produced few artificial modifications but identification to family and subfamily level possible due to wing venation. Compared to a conspecific stratiomyiid inclusion (Fig. 8) in natural amber, the setosity of the mesonotum seems to be more intense.

\section{cf. Pythidae (Coleoptera), 4 specimens, 1.5-2.5 mm}

(Figs 9, 10)

Aggregation of four coleopteran inclusions in a watery, clear amber; three specimens positioned close together near the reddish crust, with main morphological details present, surrounded by a small orange-coloured aureole. A fourth specimen positioned separately and with strongly roasted habitus; head, pronotum and prosternum with forelegs disconnected from the corpse; head capsule black, shrunk and collapsed, palpi transparent, antenna black; body black, shrunk and compressed, legs with tarsomeres brownish and transparent, integument of coxae and femora cracked at bases; elytra black, abdominal structure of sternites without any morphological details, reproductive organ extended, black to brownish, destroyed. No morphological details discernible except those of the palpi and antenna.

Identification to family level possible in the case of the three unaltered specimens; the roasted specimen can be putatively assigned to the same family due to the shape of antenna.

Autoclave processing produced no discernible artificial modifications in three of the four coleopteran inclusions, possibly because of the assumed milky emulsion covering and protecting the inclusions. The reason why the fourth specimen shows severe alterations remains speculative; perhaps it was positioned somewhat closer to the source of heating inside the device than the other ones.

\section{Rachiceridae (Diptera), cf. Electra formosa, ?male, $7.6 \mathrm{~mm}$}

(Figs 11, 12)

The dipteran inclusion is embedded in a watery, clear amber; apex of wings, terminalia and hind legs partly cut-off. Head capsule with eyes black and collapsed with fragments of ommatidia, pectinate antenna, basal antennomeres destroyed, remaining segments complete; thorax and abdomen black, roasted, collapsed and destroyed with disconnected fragments of the integument; legs transparent, collapsed, nearly flat, tibial spurs unaltered; wings partly destroyed, veins including costa with many micro-cracks.

Morphological details absent except for antenna, thus identification possible to family and genus level. Were the rachicerid-typical antenna completely destroyed, we would only be able to identify this specimen as Diptera. 


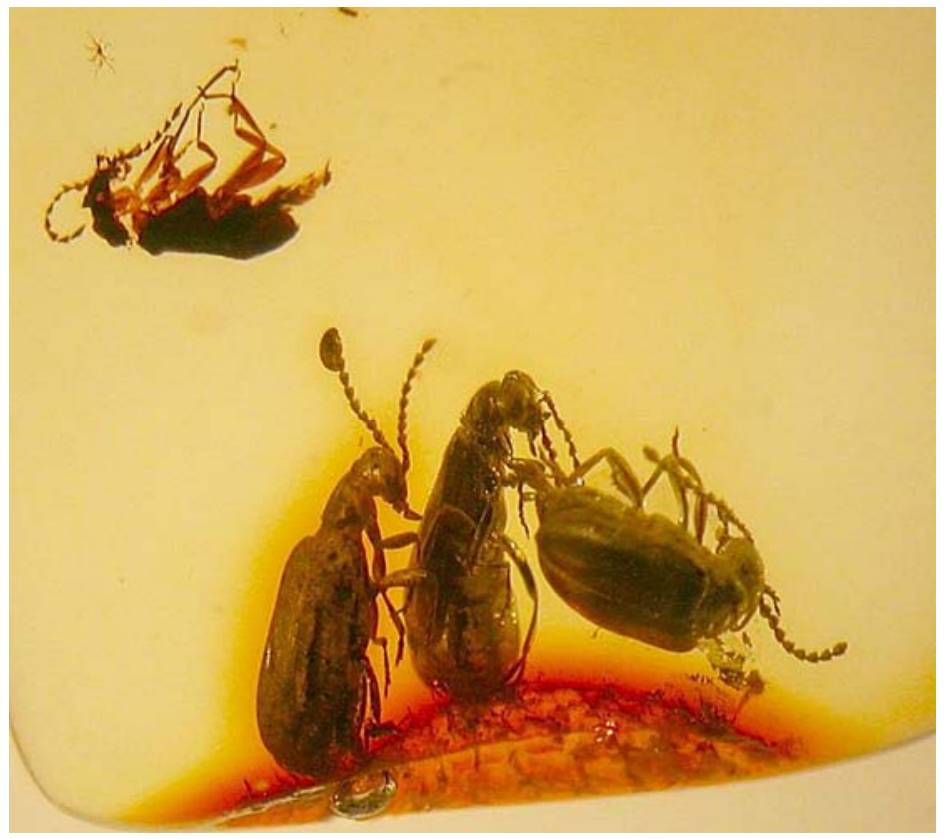

Fig. 9. cf. Pythidae (Coleoptera), 4 specimens, coll. 1588-2

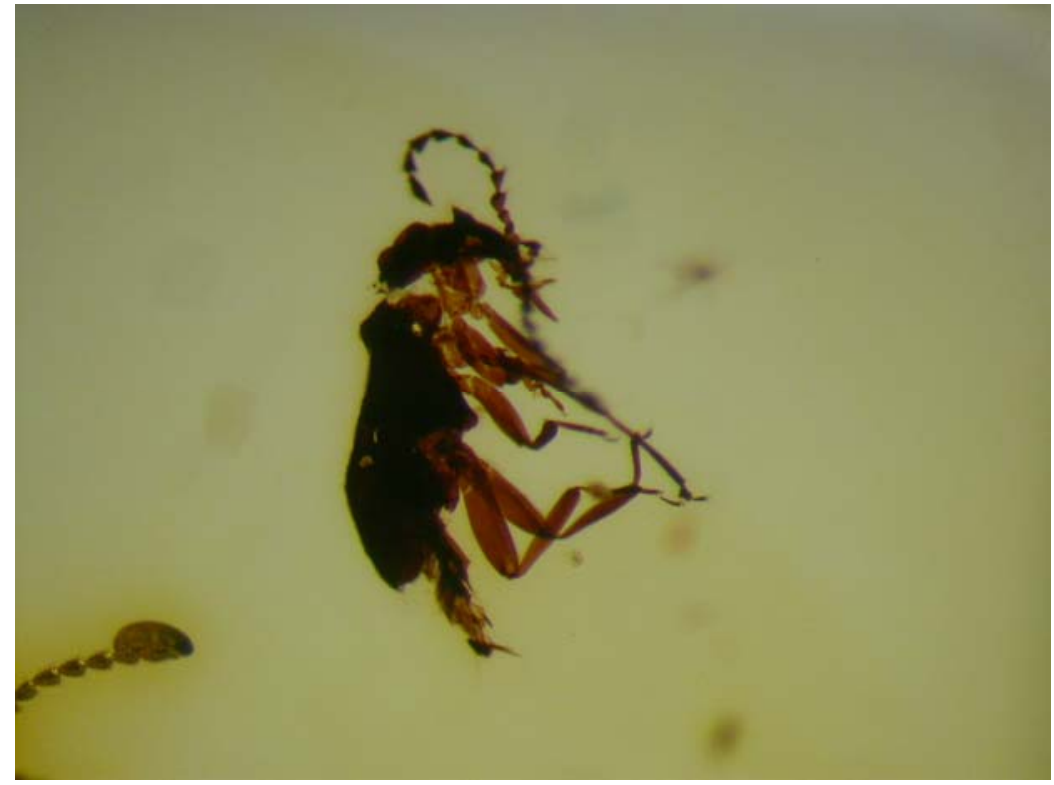

Fig. 10. cf. Pythidae (Coleoptera), roasted specimen, lateral habitus. 


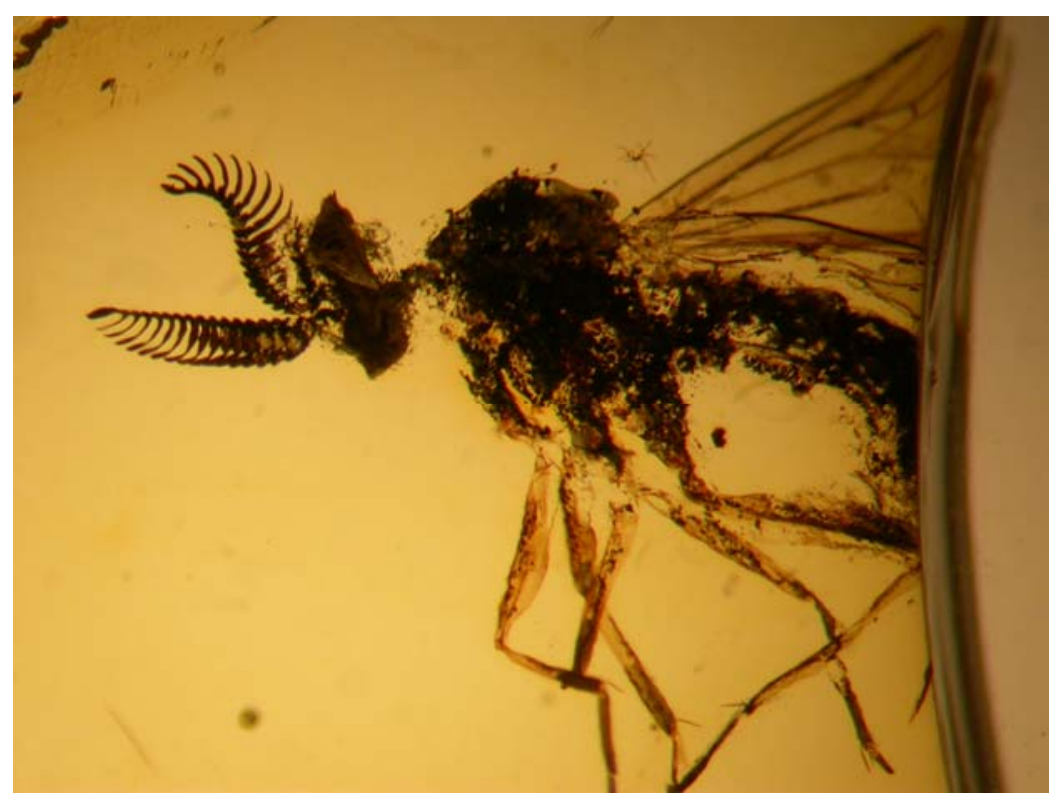

Fig. 11. Rachiceridae (Diptera), cf. Electra formosa, autoclaved ?male, habitus, coll. 1398-1.

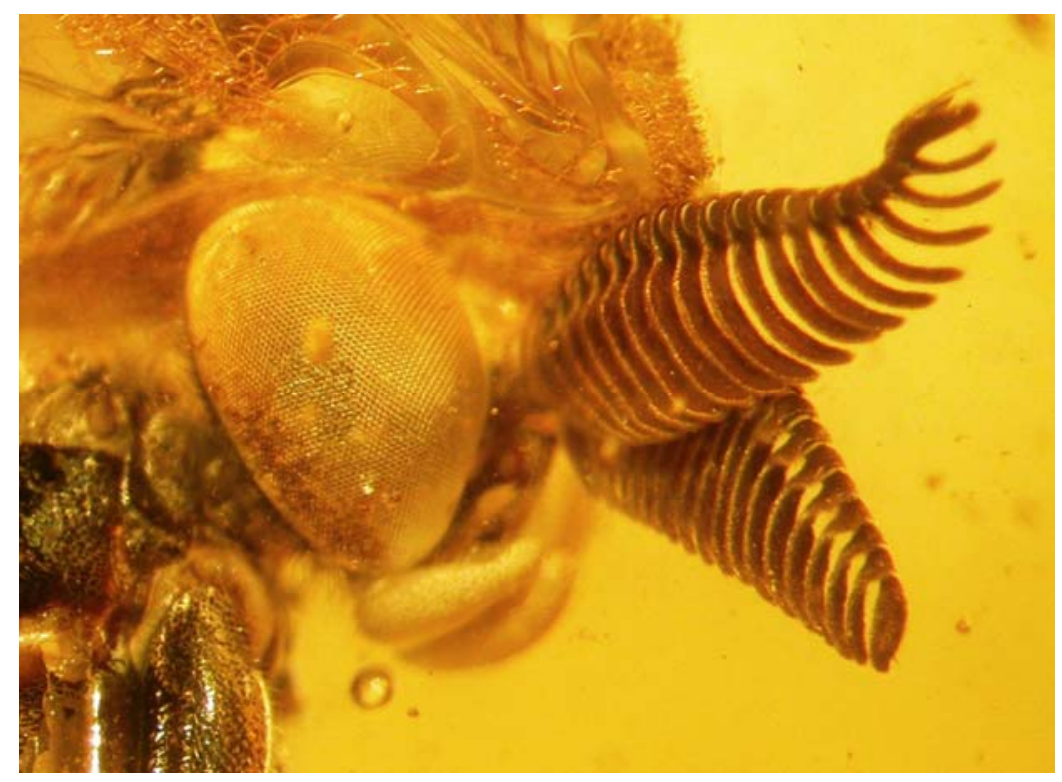

Fig. 12. Rachiceridae (Diptera, Brachycera), Electra formosa, male, head with antenna, natural amber, coll. 1104-4. 
Culicidae (Diptera), Aedes hoffeinsorum SZADZIEWSKI 1998, holotype male, $6.1 \mathrm{~mm}$ Syninclusion Pipunculidae (Diptera), female, $3.2 \mathrm{~mm}$

(Figs 13-16)

Inclusions embedded in a clear multi-layered piece of amber with intense orangecoloured resin layers. Culicid inclusion almost complete with two legs separated and close to body; head and thorax roasted, ventrally covered by a thin whitish emulsion.

All diagnostic features, like proboscis, palpi, antenna, claws, wing venation including scales, present and in good condition. Identification to family, genus and species level possible; designated as a new species. A small spot of milky coating can explain the good condition of the culicid inclusion in spite of the autoclave processing (see above).

Pipunculid syninclusion embedded in a destroyed condition with dorsally opened corpse; dorsal surface of thorax and abdomen partly above a resin flow (visible from lateral side), after entrapped in the resin the fly's corpse was eroded by scavengers (see above). Head with proboscis and typical big-headed fly eyes roasted, eyes irregularly collapsed, fragments of ommatidia remaining as micro-punctured spots; antenna porrect with elongated base, covered with long setae, postpedicellus roasted; fragments of thorax and abdomen transparent with tatters of cuticula; femora and tibia of fore legs shrunk, mid and hind legs black, pulvilli transparent; female terminalia with oviscape black and roasted, no morphological details discernible.

Identification possible to family level due to the characteristic ventrally bent oviscape present exclusively in Pipunculidae.

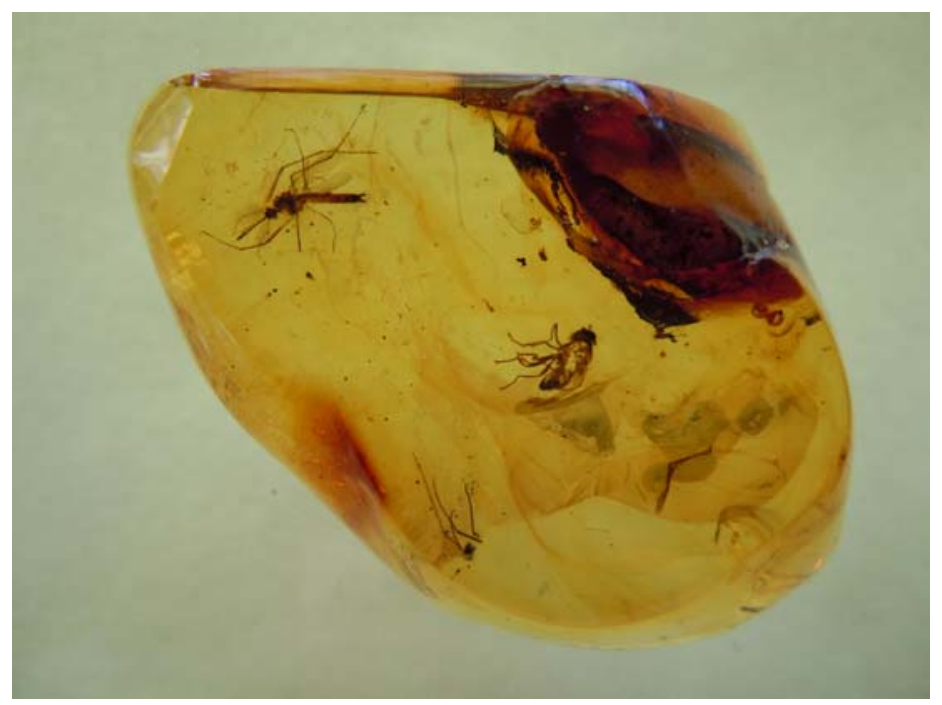

Fig. 13. Amber with Culicidae and Pipunculidae, coll. 1119. 


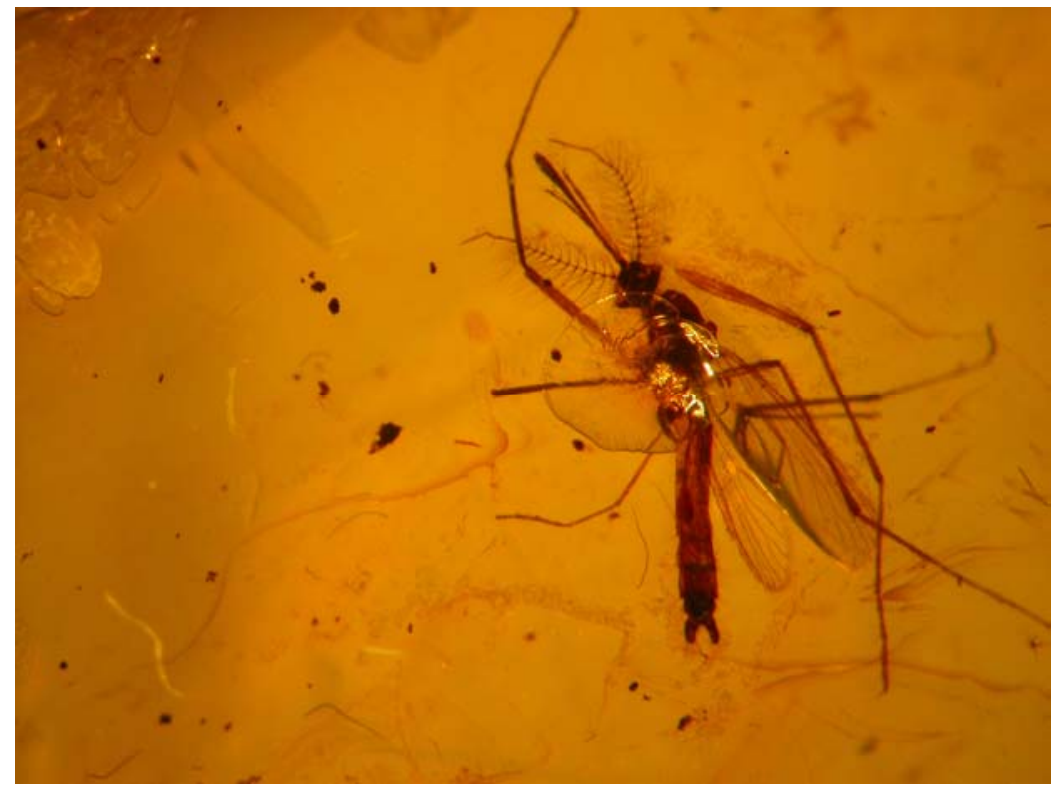

Fig. 14. Culicidae (Diptera), Aedes hoffeinsorum SZADZIEWSKI 1998, holotype male, dorsal habitus.

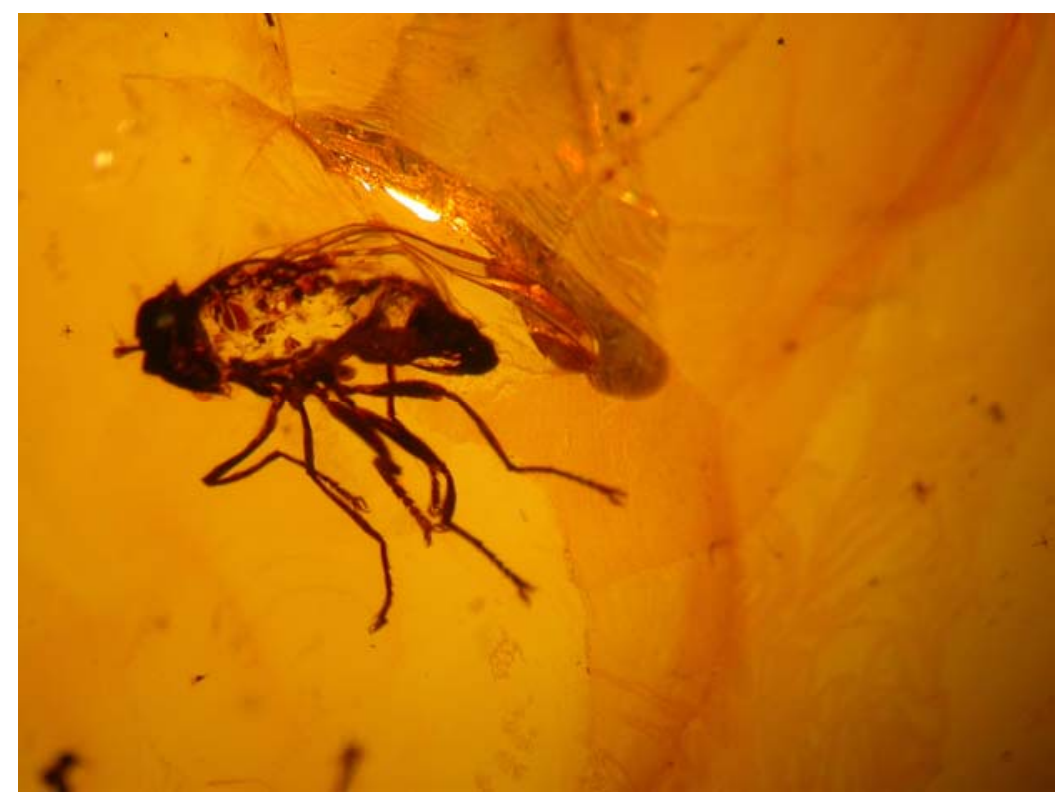

Fig. 15. Pipunculidae (Diptera), female, habitus. 


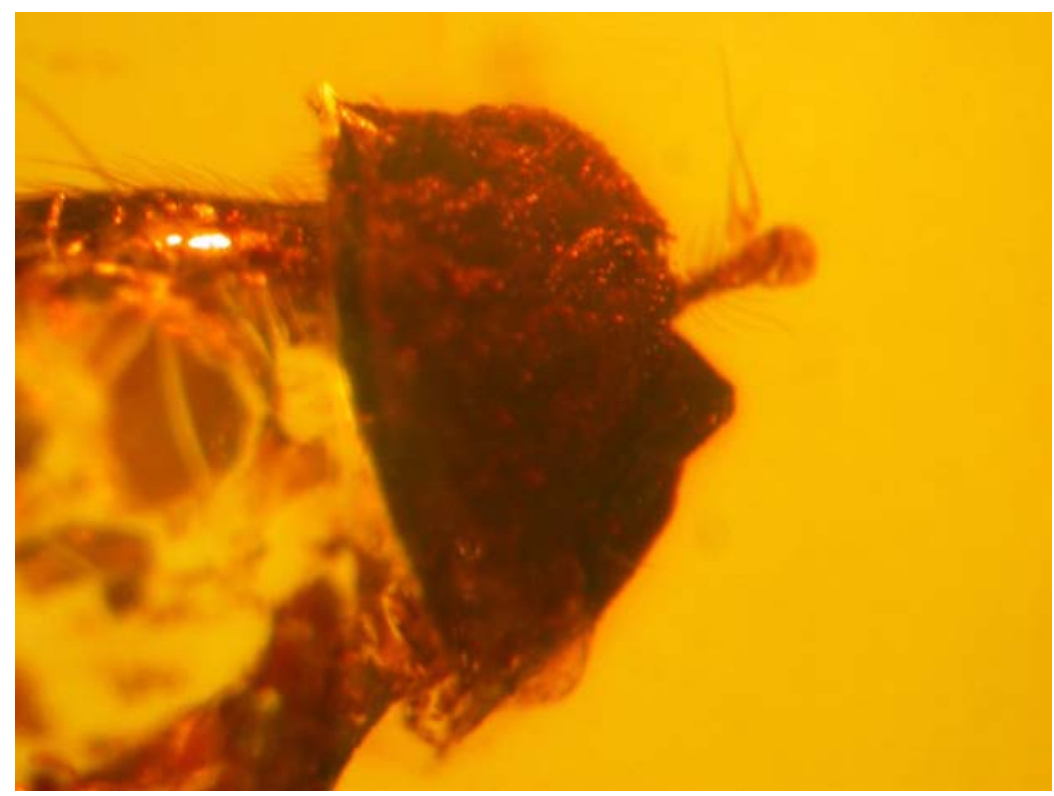

Fig. 16. Pipunculidae (Diptera), head, lateral view.

The presence of an elongated pedicellus gave rise to some questions (pers. com. C. Kehlmaier, Dresden). It remains unclear whether the elongation is a morphological character of the pipunculid inclusion or if the elongation was caused artificially by the collapse of the head capsule during treatment in the autoclave.

\section{Incertae sedis (Diptera: Acalyptratae), female, $2.3 \mathrm{~mm}$}

(Fig. 17)

Brachyceran inclusion embedded in a clear orange-coloured amber; head, thorax and abdomen black, transparent fragments of integument reddish, all parts strongly roasted, head and thorax somewhat imploded, but left eye with ommatidia almost intact, antenna transparent, 4 long peristomal seta visible, palpi well preserved; thorax and abdomen laterally compressed, original surface of mesonotum with bristle sticking in the resin above the destroyed part, several macrochaeta cracked and disconnected from mesonotum and head; legs partly transparent with complete setosity, femora cracked; wings partly destroyed at hind margin, veins with cracks.

Autoclave processing produced severe changes; identification to family level not possible because important morphological details mostly destroyed except for antenna, peristomal setae and palpi. 


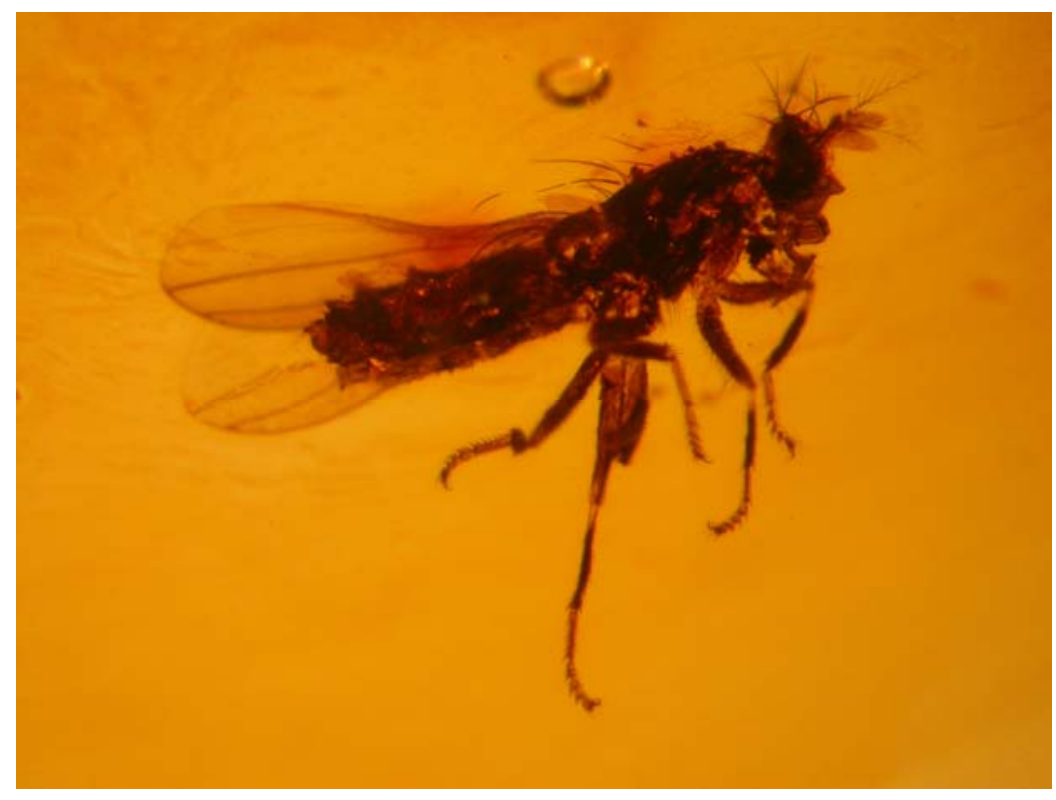

Fig. 17. Incertae sedis (Diptera, Acalyptratae), female, lateral habitus, coll. 1671-3.

The combination of plumose arista and 4 strong peristomal setae is present in Anthoclusia gephyrea within Clusiidae (HeNNIG 1965) and in Procyamops succini within Periscelididae (HofFEINS \& RUNG 2005). As the other main diagnostic characters are destroyed or not discernible, placement either in Clusiidae or Periscelididae thus remains speculative.

\section{CONCLUDING REMARKS}

Inclusions in autoclaved or "improved" amber show a broad range of artificial modifications. The main effects in a negative sense are the roasting and shrinking of body parts, black discolouration, collapsing mainly of head and eyes, compression of thorax, legs and abdomen, cracking of veins in wings, disconnection of body segments and macrochaeta.

Consequently, syninclusions embedded together in one piece of improved amber do not show an identical degree of artificial modification.

The disconnection of diagnostic macrochaeta in acalyptrate Diptera is a serious handicap in the identification to family, genus or species level.

If an inclusion is shrunk with many morphological details absent, some of the body elements such as the antenna, cerci or terminalia, as well as the setosity, are present in a well preserved condition. This is astonishing and difficult to explain. 
A positive effect of improving amber is the diffusion of the milky emulsion obscuring many inclusions. On completion of thermal treatment, the inclusions are mostly visible with the main morphological characters enabling the determination and even designation of a new taxon, as seen in the case of Aedes hoffeinsorum.

The alterations illustrated and commented on above occur with a multitude of nuances. The degree of artificial modification depends on the length of time, temperature, size of amber, size of inclusion, position of inclusion, presence of milky emulsion or a combination of these factors.

Another very serious problem is the autoclaving of sub-fossil copal material by commercial companies. The autoclave process "ages" the soft sub-fossil resin, rendering its properties similar to those of amber and making its identification as copal extremely difficult, even with advanced analytical methods. Although the use of heat treatment on a specific piece can be detected, whether or not the original starting material was copal or amber still cannot be routinely identified (MCCluRe, Kane \& STURMAn 2010: 223). Inclusions embedded in copal are more "modern" and related to the recent fauna. If such material is offered for study and the original source cannot be recognized or the information was lost in time and different trade channels, studies of these organisms may lead to very serious misinterpretations and distorted results. The prohibition and banning of copal in the amber industry should be upheld in all conditions and strictly controlled.

Palaeontologists study inclusions in Baltic amber worldwide and their published data make our knowledge of the ancient amber forest, the palaeo-environment and the palaeoclimate more clear and precise. Descriptions of new species based on material treated in an autoclave have to be investigated carefully to avoid serious misinterpretations. Each inclusion has to be checked individually. When identifying an insect or plant inclusion one has to be sure whether a certain morphological character is a species-characteristic feature or an effect of autoclave processing (SZWEDO \& SONTAG 2009).

With regard to the great richness of inclusion material, this article is published as general information for inclusion enthusiasts, collectors and specialists, indeed, for anyone interested in the fascinating world embedded in Baltic amber. This article is intended to inform entomologists and palaeontologists with less experience in amber, to help them recognize the differences between "natural" and "improved" inclusions.

\section{REFERENCES}

McClure S.F., Kane R.E., Sturman N. 2010. Gemstone enhancement and its detection in the 2000s. Gems and Gemmology 46(3): 218-240.

HeNNIG W. 1965. Die Acalyptratae des Baltischen Bernsteins und ihre Bedeutung für die Erforschung der phylogenetischen Entwicklung dieser Dipteren-Gruppe. Stuttgarter Beiträge zur Naturkunde 145: 1-215. 
MiERZEJEWSKI P. 1978. Electron microscopy study on the milky impurities covering arthropod inclusions in the Baltic amber. Prace Muzeum Ziemi, Prace geologiczne 28: 79-84.

SCHLÜTER T., KÜHNE W.G. 1975. Die einseitige Trübung von Harzinklusen - ein Indiz gleicher Bildungsumstände. Entomologica Germanica, Stuttgart 2: 308-315.

SzADZIEwSKi R.1998. New mosquitoes from Baltic amber (Diptera: Culicidae). Polish Journal of Entomology 67: 233-244.

Szwedo J., SonTAG E. 2009. The traps of the "amber trap". How inclusions could trap scientists with enigmas. Denisia 26: 155-169.

Von Tschirnhaus M., Hoffeins C. 2009. Fossil flies in Baltic amber - insights in the diversity of Tertiary Acalyptratae (Diptera, Schizophora), with new morphological characters and a key based on 1,000 collected inclusions. Denisia 26: 171-212.

Weitschat W., Wichard W. 1998. Atlas der Pflanzen und Tiere in Baltischen Bernstein. Verlag Dr. Friedrich Pfeil, München, 256 pp.

Received: March 16, 2012

Accepted: May 10, 2012 